\title{
ANALISIS PERENCANAAN PRIORITAS JARINGAN JALAN UNTUK PENGEMBANGAN WILAYAH DI KABUPATEN TANA TORAJA
}

\section{Analysis of Priority Road Network Planning for Regional Development in Tana Toraja}

\author{
Gersony Miri1)*, Baba Barus ${ }^{2)}$, dan Soekmana Soma ${ }^{3)}$ \\ 1) Alumni Program Studi Ilmu Perencanaan Wilayah, Sekolah Pascasarjana IPB, Jl. Raya Darmaga, Gedung Andi \\ Hakim Nasoetion Kampus IPB Darmaga Bogor 16680 \\ 2) Departemen Ilmu Tanah dan Sumberdaya Lahan, Fakultas Pertanian IPB, Jl. Meranti Kampus IPB Darmaga \\ Bogor 16680 \\ 3) Pusdiklat, Kementerian Pekerjaan Umum dan Perumahan Rakyat, J1. Sapta Taruna Raya Komplek PU Pasar \\ Jumat, Jakarta
}

\begin{abstract}
The road network is one of the supporting economic activities that lead to the improvement of people's lives. Tana Toraja district has 166 roads with a total length of 1,252.0 km that most (74.24\%) are in poor condition. This is due to the policy regarding budget constraints, consequently all roads can not be handled entirely, thus requiring priority road network that need to be addressed for the future development of the region. This study uses schallogram analysis to identify areas which become service center for its hinterland and methods of analytical hierarchy process (AHP) to obtain stakeholders views on the priority factor in selecting a network path will be handled. The results showed 2 districts are service centers (Hierarchy I), 5 districts are service sub-centers (Hierarchy II), and 12 districts are hinterland (Hierarchy III). AHP analysis obtained from the priority road network selection based on potential tourist attraction. So that the road network can be prioritized are: 1). Alternative I, which consists of: (i) ring road travel, (ii) Kokkang - Buakayu, (iii) Pasobo - Kondodewata, (iv) Tetebassi-Kondoran, (v) Batupapan - Rantekurra; 2). Alternative II, which consists of: (i) ring road travel, (ii) Kokkang - Buakayu, (iii) Pasobo - Kondodewata, (iv) Tetebassi-Kondoran, (v) Batupapan - Rantekurra, (vi) Makale - Kaduaja.
\end{abstract}

Keywords: Analytical Hierarchy Process, road network, schallogram, Tana Toraja

\begin{abstract}
ABSTRAK
Jaringan jalan merupakan salah satu penunjang kegiatan perekonomian yang bermuara pada peningkatan taraf hidup masyarakat. Kabupaten Tana Toraja memiliki 166 ruas jalan kabupaten dengan total panjang 1,252 km yang sebagian besar (74.24\%) berada dalam kondisi rusak. Hal ini disebabkan oleh adanya kebijakan pendanaan karena keterbatasan anggaran, akibatnya semua ruas jalan tidak dapat tertangani seluruhnya, sehingga membutuhkan prioritas jaringan jalan yang perlu ditangani untuk pengembangan wilayahnya ke depan. Penelitian ini menggunakan metode analisis skalogram untuk mengidentifikasi wilayah-wilayah yang menjadi pusat pelayanan dan metode Analytical Hierarchy Process (AHP) untuk mendapatkan persepsi stakeholder terhadap faktor yang menjadi prioritas dalam memilih jaringan jalan yang akan ditangani. Hasil penelitian menunjukkan 2 kecamatan merupakan pusat pelayanan (Hirarki I), 5 kecamatan merupakan subpusat pelayanan (Hirarki II), dan 12 kecamatan merupakan wilayah hinterland (Hirarki III). Dari analisis AHP diperoleh pilihan prioritas jaringan jalan berdasarkan potensi obyek wisata. Sehingga jaringan jalan yang dapat diprioritaskan adalah: 1). Alternatif I, terdiri atas: (i) Jalan lingkar wisata, (ii) Kokkang - Buakayu, (iii) Pasobo - Kondodewata, (iv) Tetebassi Kondoran, (v) Batupapan - Rantekurra; 2). Alternatif II, terdiri atas: (i) Jalan lingkar wisata, (ii) Kokkang - Buakayu, (iii) Pasobo - Kondodewata, (iv) Tetebassi - Kondoran, (v) Batupapan - Rantekurra, (vi) Makale - Kaduaja.
\end{abstract}

Kata kunci: Analytical Hierarchy Process, jaringan jalan, skalogram, Tana Toraja

\section{PENDAHULUAN}

Tersedianya jaringan prasarana transportasi yang menghubungkan ke seluruh kota dan pusat produksi di seluruh wilayah memberikan kesempatan dan mendorong pengembangan dan peningkatan pertumbuhan ekonomi daerah.

Kabupaten Tana Toraja yang memiliki luas wilayah $\pm 2,054.3 \mathrm{~km}^{2}$ dengan kepadatan penduduk mencapai 108 jiwa $\mathrm{km}^{-2}$ (BPS Kab. Tana Toraja, 2010) merupakan wilayah yang sangat berpotensi dalam pengembangan wilayahnya ke depan. Berdasarkan Peraturan Menteri PU No.14/PRT/M/2010 tentang Standar Pelayanan Minimal Bidang Pekerjaan Umum dan Penataan Ruang, maka indeks mobilitas pelayanan jaringan jalan di kabupaten Tana Toraja masuk pada kategori II yaitu minimal $11.0 \mathrm{~km}$ 10,000 jiwa ${ }^{-1}$ (Tabel 1). Kabupaten Tana Toraja sendiri memiliki 166 ruas jalan kabupaten dengan panjang total 
$1,252.0 \mathrm{~km}$ yang tersebar di 19 kecamatan. Sehingga angka mobilitas Kabupaten Tana Toraja pada tahun 2011

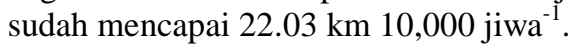

Namun kenyataannya, pemerintah daerah masih saja terus melakukan pembukaan ruas jalan baru, sementara ruas jalan yang sudah ada kurang mendapat perhatian yang ditandai dengan kondisi ruas-ruas jalan tersebut banyak dalam keadaan rusak. Pemerintah daerah seharusnya meningkatkan dan memelihara jaringan jalan yang sudah ada untuk kelancaran aksesibilitas agar lebih mendorong pertumbuhan ekonomi dalam rangka peningkatan kesejahteraan masyarakatnya. Juga dengan terlalu banyaknya jaringan jalan yang ada, dengan sendirinya akan membutuhkan biaya pemeliharaan yang cukup besar, sementara pemerintah daerah masih terkendala oleh keterbatasan dana penanganan jalan. Oleh karena itu, diperlukan perencanaan prioritas jaringan jalan agar penanganannya menjadi lebih efektif dan efisien.

Tabel 1. Angka mobilitas yang ditentukan berdasarkan kerapatan penduduk

\begin{tabular}{ccc}
\hline Kategori & $\begin{array}{c}\text { Kerapatan Penduduk } \\
\left(\text { jiwa km }^{-2}\right)\end{array}$ & $\begin{array}{c}\text { Angka Mobilitas } \\
\left(\mathrm{km} \mathrm{10,000} \mathrm{jiwa}^{-1}\right)\end{array}$ \\
\hline I & $<100$ & 18.50 \\
II & $100 \leq \mathrm{KP}<500$ & 11.00 \\
III & $500 \leq \mathrm{KP}<1000$ & 5.00 \\
IV & $1000 \leq \mathrm{KP}<5000$ & 3.00 \\
V & $\geq 5000$ & 2.00 \\
\hline Sumber: & Lampiran II & Permen PU No.14/PRT/M/2010 tanggal 25 \\
& Oktober 2010 &
\end{tabular}

Penelitian ini bertujuan untuk mendapatkan kesesuaian antara jaringan jalan dengan potensi-potensi wilayah Kabupaten Tana Toraja, mengkonstruksikan persepsi stakeholder terhadap perencanaan jaringan jalan di Kabupaten Tana Toraja, dan menyusun perencanaan prioritas jaringan jalan di Kabupaten Tana Toraja untuk pengembangan wilayahnya ke depan.

\section{BAHAN DAN METODE}

Penelitian dilakukan di Kabupaten Tana Toraja yang meliputi 19 kecamatan. Secara geografis Kabupaten Tana Toraja terletak di bagian Utara Provinsi Sulawesi Selatan yaitu antara $2^{\circ}-3^{\circ}$ Lintang Selatan dan $119^{\circ}$ $120^{\circ}$ Bujur Timur, dengan luas wilayah tercatat $2,054.30$ $\mathrm{km}^{2}$.

Data primer yang digunakan diperoleh melalui kuesioner dari responden yang dianggap mempunyai kemampuan dan mengerti permasalahan terkait dengan pengembangan jaringan jalan di Kabupaten Tana Toraja. Oleh karena itu, metode pengambilan sampel dalam analisis ini menggunakan metode purposive sampling. Sementara data sekunder yang digunakan diperoleh dari berbagai instansi terkait.

Adapun metode analisis data dalam penelitian ini menggunakan metode analisis deskriptif, analisis skalogram, Analytical Hierarchy Process (AHP), dan sintesis logika.

\section{HASIL DAN PEMBAHASAN}

\section{Identifikasi Potensi Wilayah}

\section{Kepadatan Penduduk}

Penduduk Kabupaten Tana Toraja tahun 2011 berjumlah 223,306 jiwa yang tersebar di 19 kecamatan, dimana Kecamatan Makale sebagai lokasi ibukota kabupaten memiliki kepadatan penduduk terbesar yaitu 857 jiwa $\mathrm{km}^{-2}$ dan yang terkecil adalah Kecamatan Simbuang dengan kepadatan 32 jiwa $\mathrm{km}^{-2}$.

\section{Tanaman Pangan}

Potensi tanaman pangan yang dominan di Kabupaten Tana Toraja adalah padi. Produksi padi di Kabupaten Tana Toraja tahun 2011 sebesar 110,456 ton yang dipanen dari areal seluas 21,223 ha, atau menghasilkan rata-rata 5.2 ton $\mathrm{ha}^{-1}$. Wilayah kecamatan yang memiliki produksi tertinggi adalah Kecamatan Mengkendek dengan jumlah produksi mencapai 15,734 ton. Sedangkan wilayah kecamatan yang paling rendah produksinya adalah Kecamatan Mappak dengan total produksi 1,234 ton.

Selain tanaman padi, di Kabupaten Tana Toraja juga terdapat beberapa tanaman palawija seperti: jagung, kacang tanah, kacang kedelai, ubi kayu, dan ubi jalar. Produksi tanaman palawija di Kabupaten Tana Toraja pada tahun 2011 sebesar 246,921.9 ton. Wilayah kecamatan yang memiliki produksi tertinggi adalah Kecamatan Bonggakaradeng dengan jumlah produksi mencapai 63,219.9 ton. Sedangkan wilayah kecamatan yang paling rendah produksinya adalah Kecamatan Makale Utara dengan total produksi 3,101.3 ton. Gambar 1 menunjukkan peta potensi wilayah Kabupaten Tana Toraja.

\section{Pariwisata}

Pariwisata merupakan produk unggulan Kabupaten Tana Toraja untuk dapat meningkatkan pertumbuhan ekonominya. Pengelolaan potensi pariwisata di daerah ini menjadi perhatian khusus pemerintah daerah, hal ini tercermin dalam arah kebijakan (visi) pemerintah bahwa tujuan utama pembangunan pariwisata adalah menjadikan Tana Toraja sebagai destinasi kedua setelah Bali. Oleh karena potensi pariwisatanya, Kabupaten Tana Toraja ditetapkan sebagai salah satu Kawasan Strategis Nasional dan masuk dalam daftar World Heritage Culture oleh UNESCO. Di sisi lain, dukungan masyarakat Tana Toraja sangat positif memberikan respon pengembangan pariwisata. Banyak masyarakat yang bergantung dari hasil penjualan hasil karya budaya (kain tenun, ukiran). Jumlah wisatawan domestik pada tahun 2011 tercatat 15,867 orang. Jumlah wisatawan mancanegara pada tahun 2011 tercatat 3,624 orang. Gambar 2 menunjukkan tren kunjungan wisatawan dari tahun 2007 - 2011. 


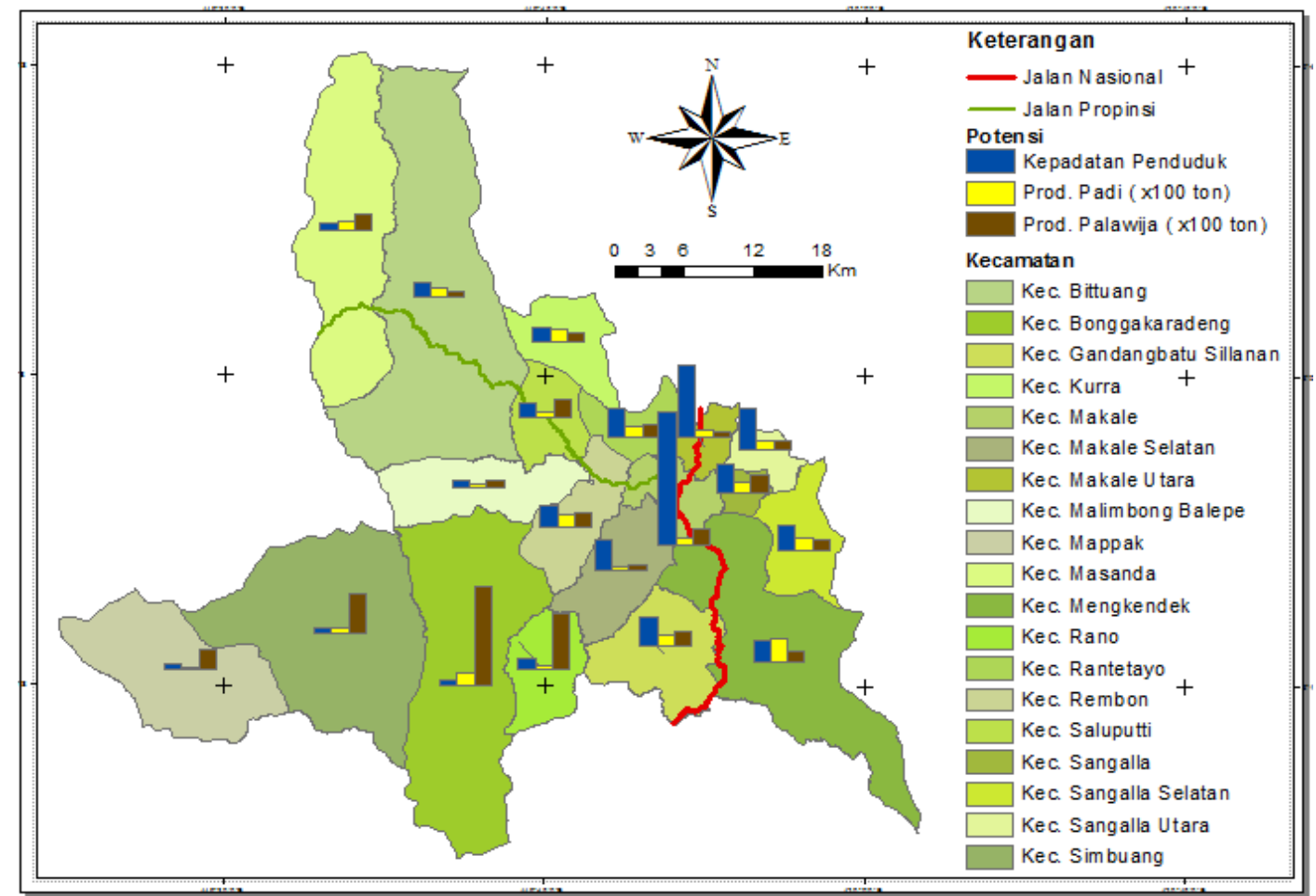

Gambar 1. Peta potensi wilayah Kabupaten Tana Toraja tahun 2011

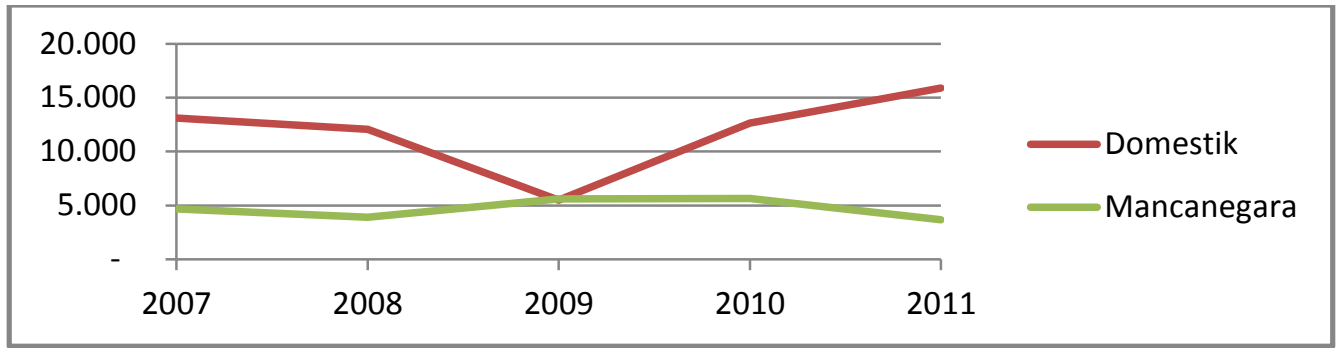

Gambar 2. Tren kunjungan wisatawan domestik dan mancanegara di Kabupaten Tana Toraja tahun 2007 - 2011

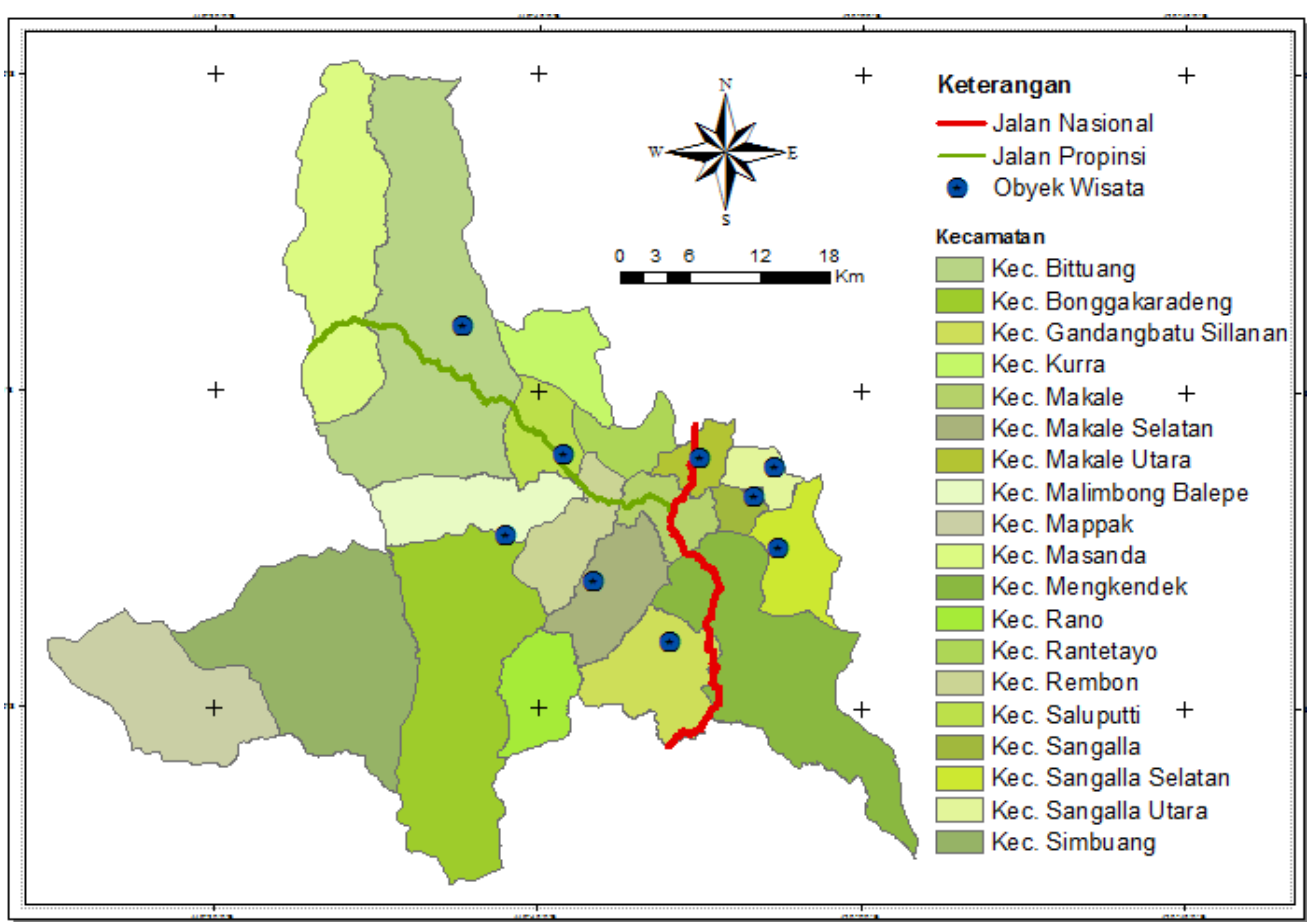

Gambar 3. Peta lokasi obyek wisata Kabupaten Tana Toraja 


\section{Sistem Jaringan Jalan Kabupaten}

Prasarana jalan di Kabupaten Tana Toraja terdiri dari jalan nasional $43 \mathrm{~km}$, jalan propinsi $40 \mathrm{~km}$, dan jalan kabupaten 1,252 km. Khusus untuk jalan kabupaten, jenis permukaan jalannya sebagian besar berupa jalan tanah, yaitu $43.69 \%$ dari total seluruh panjang jalan kabupaten. Sementara kondisi permukaan jalan kabupaten di Kabupaten Tana Toraja masih sebagian besar dalam kondisi rusak yakni sekitar 74.24\% (Tabel 2).

Tabel 2. Jenis permukaan dan kondisi jalan Kabupaten Tana Toraja

\begin{tabular}{crlcc}
\hline & & Keadaan & Panjang $(\mathrm{km})$ & Proporsi (\%) \\
\hline I. & & Jenis Permukaan : & & \\
& a. & Aspal & 290.90 & 23.23 \\
& b. & Beton & 103.20 & 8.24 \\
& c. & Kerikil/Pengerasan & 310.95 & 24.84 \\
& d. & Tanah & 546.95 & 43.69 \\
II. & & Kondisi Jalan : & & \\
& a. & Baik & 146.95 & 11.74 \\
& b. & Sedang & 175.50 & 14.02 \\
& c. & Rusak Ringan & 295.75 & 23.62 \\
& d. & Rusak Berat & 633.80 & 50.62 \\
\hline
\end{tabular}

Sumber : Dinas PU (2011)
Kondisi di atas memperlihatkan bahwa tingkat kemampuan jaringan jalan di Kabupaten Tana Toraja masih dibawah rata-rata untuk memenuhi pergerakan kendaraan secara cepat dan lancar. Hal ini mempengaruhi pertumbuhan ekonomi wilayah karena akan meningkatkan biaya transportasi terhadap nilai ekonomi suatu produksi barang/jasa (Taiwo dan Francis, 2013).

\section{Pola Pergerakan}

Potensi pergerakan antar kecamatan di Kab. Tana Toraja dipengaruhi oleh 3 hal, yaitu: i). kegiatan pasar pada hari pasar, ii). upacara perkawinan, iii). upacara kematian. Jumlah angkutan umum berdasarkan jaringan trayek yang ada, sebagian besar masih didominasi oleh rute/trayek dalam ibukota kabupaten dan trayek yang menghubungkan dengan kabupaten tetangga. Sehingga hal ini dapat menggambarkan bahwa pola pergerakan umum di Kabupaten Tana Toraja masih terpusat pada sekitar ibukota kabupaten (Kecamatan Makale). Sementara pergerakan di dalam kabupaten sendiri (antar kecamatan) belum begitu signifikan. Tabel 3 menunjukkan jumlah angkutan umum berdasarkan trayek pada tahun 2009 2011.

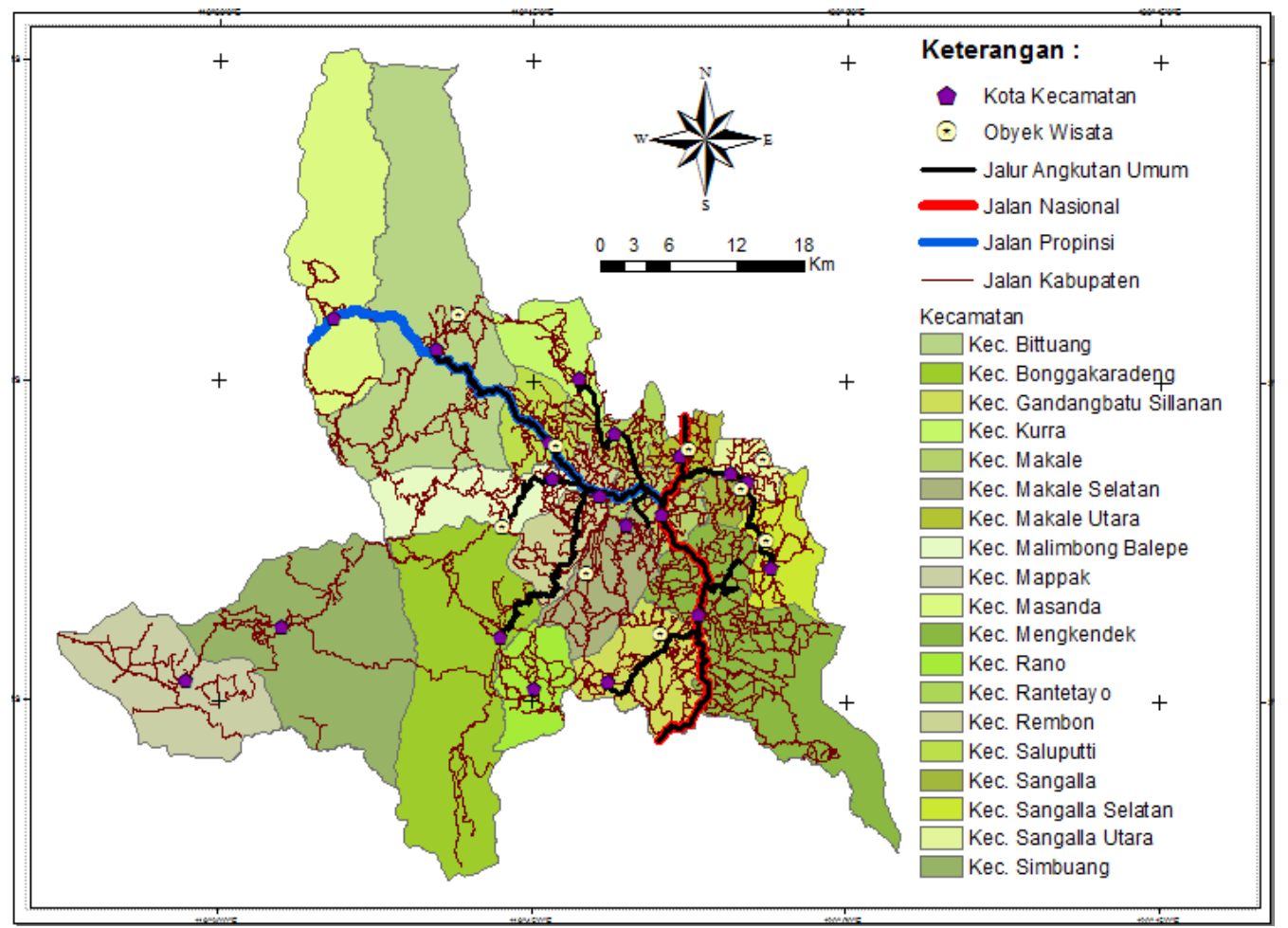

Gambar 4. Peta jaringan trayek angkutan umum

\section{Struktur Ruang Wilayah Kabupaten}

Rencana sistem perkotaan wilayah kabupaten terdiri atas: (i) Pusat kegiatan lokal yang berfungsi untuk melayani kegiatan skala kabupaten sehingga ditempatkan di ibukota kabupaten, (ii) Pusat pelayanan kawasan yang berfungsi untuk melayani kegiatan skala kecamatan, sehingga ditempatkan di setiap ibukota kecamatan, (iii) Pusat pelayanan lokal yang berfungsi untuk melayani kegiatan skala antar desa sehingga ditempatkan pada beberapa desa.
Rencana jaringan lalu lintas angkutan jalan di Kabupaten Tata Toraja, terdiri atas: (i) Jaringan jalan kolektor primer yang merupakan sistem jaringan jalan nasional, terdiri atas: Batas Kabupaten Enrekang - Makale - Batas Kabupaten Toraja Utara; (ii) Jaringan jalan kolektor primer yang merupakan sistem jaringan jalan propinsi, terdiri atas: Makale - Batas Kabupaten Mamasa, Kokkang - Buakayu - Bau - Batas Kabupaten Pinrang, Pa'tengko - Kondoran - Sandale - Buntao (batas Kabupaten Toraja Utara); (iii) Jaringan jalan kabupaten, yang terdiri atas: Pasobo - Matangli - Lekke - Saruran (batas Kabupaten Mamasa), Tetebassi - Kondoran - 
Makula - Batualu - Batas Kabupaten Luwu, jalan lokal primer lingkar wisata, jalan lokal primer penghubung pusat produksi pertanian di setiap kota kecamatan, jalan lokal primer penghubung ke obyek-obyek wisata, jalan lokal primer penghubung ke pusat-pusat permukiman di seluruh wilayah kabupaten.

Tabel 3. Jumlah angkutan umum berdasarkan trayek tahun 2009 - 2011

\begin{tabular}{|c|c|c|c|c|}
\hline \multirow{2}{*}{ No. } & \multirow{2}{*}{ Jaringan Trayek } & \multicolumn{3}{|c|}{ Jumlah Kendaraan } \\
\hline & & 2009 & 2010 & 2011 \\
\hline 1 & Terminal Makale - Terminal Bolu (Toraja Utara) & 191 & 185 & 231 \\
\hline 2 & Terminal Makale - Sangalla - Batualu & 51 & 67 & 52 \\
\hline 3 & Terminal Makale - Rantetayo - Kurra & 38 & 35 & 35 \\
\hline 4 & Terminal Makale - Ulusalu - Bittuang & 65 & 79 & 73 \\
\hline 5 & Terminal Makale - Malimbong & 5 & 7 & 13 \\
\hline 6 & Terminal Makale - Batusura - Buakayu & 42 & 35 & 40 \\
\hline 7 & Terminal Makale - Turunan & 2 & 0 & 0 \\
\hline 8 & Terminal Makale - Mebali - Buntu & 21 & 16 & 17 \\
\hline 9 & Terminal Makale - Marinding & 2 & 5 & 0 \\
\hline 10 & Terminal Makale - Palipu & 2 & 0 & 0 \\
\hline 11 & Terminal Makale - Tampo & 13 & 13 & 11 \\
\hline 12 & Terminal Makale - Salubarani - Sudu (Enrekang) & 61 & 91 & 100 \\
\hline 13 & Terminal Makale - Dalam Kota/Kecamatan Makale & 165 & 230 & 294 \\
\hline & Total & 658 & 763 & 866 \\
\hline
\end{tabular}

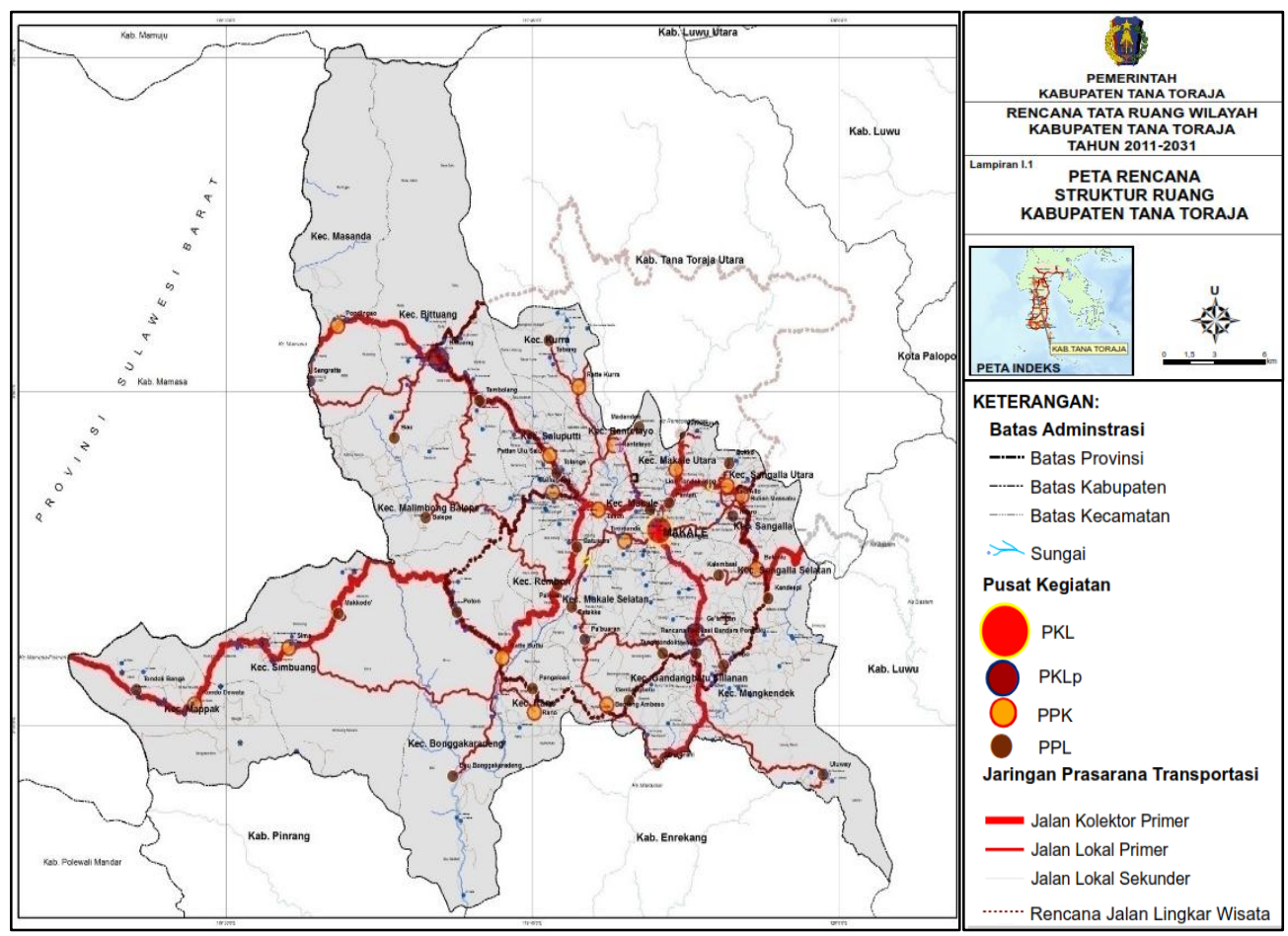

Sumber : RTRW Kabupaten Tana Toraja 2011

Gambar 5. Peta rencana struktur ruang Kabupaten Tana Toraja

\section{Identifikasi Pusat-Pusat Pertumbuhan Wilayah}

Dalam teori kutub pertumbuhan yang dikembangkan oleh Francois Perraoux (Christofakis dan
Papadaskalopoulos, 2011) bahwa pertumbuhan suatu wilayah terjadi pada titik-titik tertentu atau kutub wilayah sehingga akan menyebabkan adanya pusat-pusat pelayanan terhadap wilayah-wilayah yang kurang berkembang. 


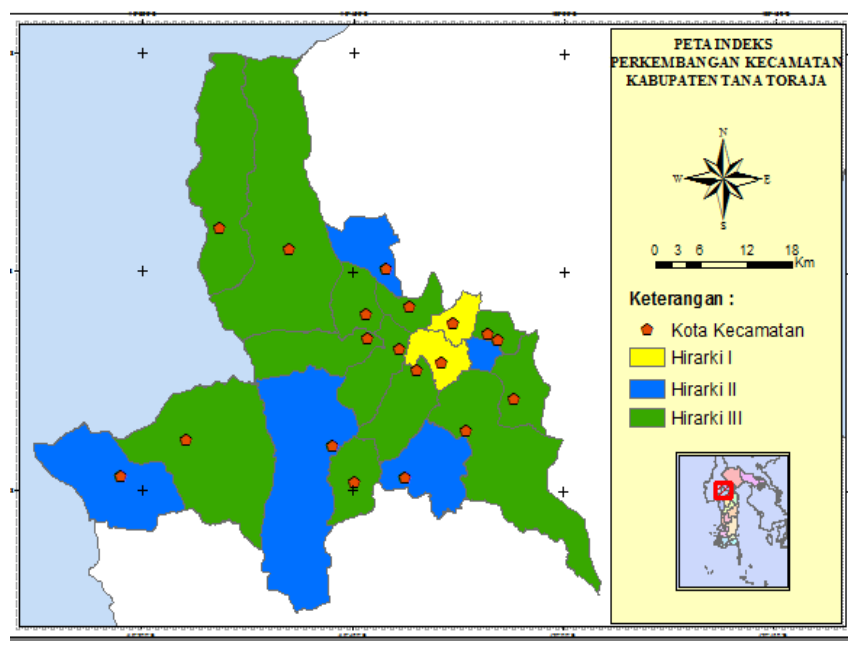

Gambar 6. Peta hirarki wilayah

Berdasarkan hasil perhitungan analisis skalogram yang telah dilakukan dengan menggunakan 34 variabel jumlah dan jenis fasilitas pelayanan/infrastruktur, diperoleh 3 hirarki wilayah, yaitu:

i). Hirarki I sebagai pusat pelayanan, dicirikan dengan indeks perkembangan (IP) $>$ 41.57. Kecamatan yang masuk dalam hirarki I ini adalah: Kecamatan Makale dan Makale Utara.

ii). Hirarki II sebagai subpusat pelayanan, dicirikan dengan IP antara 26.12 (IP rataan) - 41.57. Kecamatan yang masuk dalam hirarki II ini adalah:
Kecamatan Bonggakaradeng, Mappak, Gandangbatu Sillanan, Sangalla, dan Kurra.

iii). Hirarki III sebagai hinterland, dicirikan dengan IP $<26.12$. Kecamatan yang masuk dalam hirarki III ini adalah: Kecamatan Simbuang, Rano, Mengkendek, Sangalla Selatan, Sangalla Utara, Makale Selatan, Saluputti, Bittuang, Rembon, Masanda, Malimbong Balepe, dan Rantetayo.

\section{Analisis AHP (Analytical Hierarchical Process)}

Untuk mengetahui faktor prioritas dalam memilih jaringan jalan dengan melibatkan masyarakat/stakeholder dilakukan dengan analisis AHP. Menurut Saaty dan Sodenkamp (2008), AHP adalah suatu pendekatan pengambilan keputusan yang dirancang untuk membantu pencarian solusi dari berbagai permasalahan multikriteria yang kompleks dalam sejumlah ranah aplikasi.

Dari hasil analisis AHP di atas (Gambar 7), diperoleh faktor yang menjadi prioritas dalam memilih jaringan jalan berdasarkan potensi wilayah, yaitu: obyek wisata, pusat administrasi pemerintahan, dan kepadatan penduduk. Sementara faktor pasar dan pertanian mendapatkan bobot jauh lebih rendah, menunjukkan persepsi stakeholder bahwa pengembangan jalan karena pasar dan pertanian kurang diprioritaskan. Untuk faktor yang berdasarkan aksesibilitas, diperoleh kondisi jalan dan volume lalu lintas menjadi lebih prioritas dibanding dengan faktor penghematan waktu tempuh.

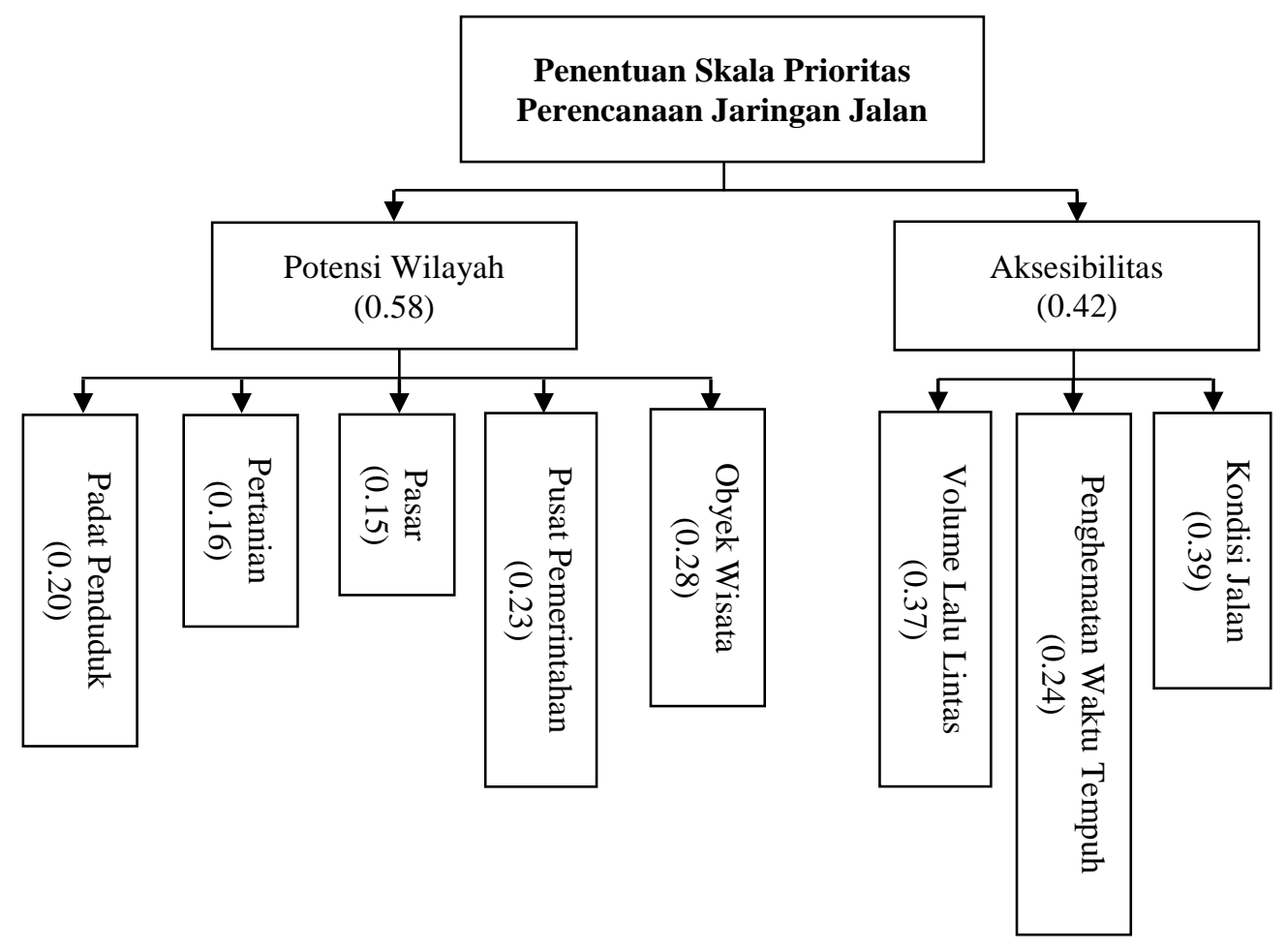

Gambar 7. Bobot hirarki skala prioritas jaringan jalan Kabupaten Tana Toraja

\section{Sintesis Prioritas Jaringan Jalan}

Menurut teori lokasi pusat (Christaller dalam Tarigan, 2009), bahwa dalam memenuhi kebutuhan barang dan jasa konsumen bergerak menuju pusat terdekat. Dimana pusat wilayah berfungsi sebagai: (i) tempat terkonsentrasinya penduduk, (ii) pusat pelayanan terhadap daerah hinterland, (iii) pasar bagi komoditas pertanian maupun industri, (iv) lokasi pemusatan industri manufaktur. Sementara hinterland, berfungsi sebagai: (i) pemasok bahan-bahan mentah/baku, (ii) pemasok tenaga 
kerja melalui urbanisasi dan commuting, (iii) daerah pemasaran barang dan jasa, (iv) penjaga keseimbangan ekologis (Rustiadi et al., 2011)

Dari hasil-hasil analisis sebelumnya, maka digunakan beberapa pendekatan dan kriteria dalam memilih jaringan jalan yang dapat diprioritaskan, yaitu : (i) Ruas jalan yang umumnya dilalui oleh trayek angkutan umum; (ii) Ruas jalan yang memiliki klasifikasi fungsi yang lebih tinggi berdasarkan penetapan status jalan kabupaten oleh Bupati; (iii) Ruas jalan yang direncanakan dalam RTRW kabupaten.
Sehingga diperoleh jaringan jalan yang menjadi prioritas untuk pengembangan wilayah di Kabupaten Tana Toraja, yaitu :

1. Alternatif I dengan total panjang jalan $224.1 \mathrm{~km}$, yang terdiri atas: (i). Batupapan - Rantekurra dengan panjang $16.9 \mathrm{~km}$; (ii). Kokkang - Buakayu dengan panjang $25.4 \mathrm{~km}$; (iii). Pasobo - Kondodewata dengan panjang $73.5 \mathrm{~km}$; (iv). Tetebassi - Kondoran dengan panjang $8.6 \mathrm{~km}$; (v). Jalan lingkar wisata dengan panjang $99.7 \mathrm{~km}$.

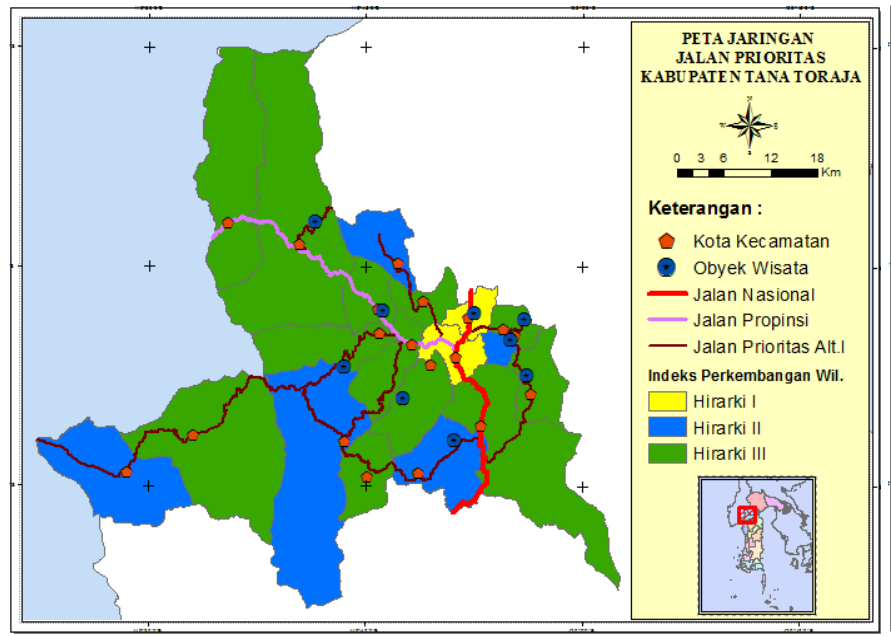

(a)

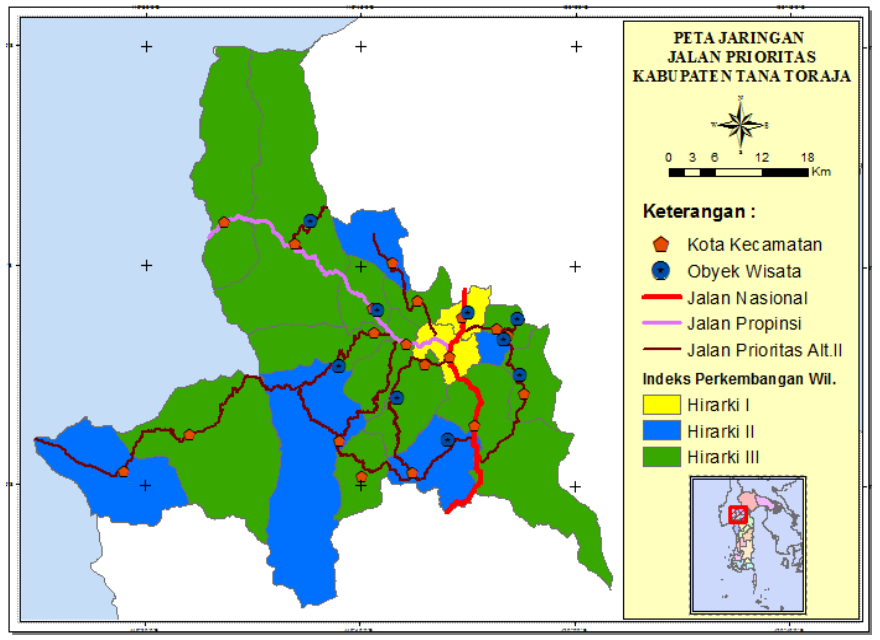

(b)

Gambar 8. Peta prioritas jaringan jalan alternatif i (a) dan peta prioritas jaringan jalan alternatif ii (b)

Ruas-ruas jalan pada alternatif I ini merupakan ruasruas jalan trayek angkutan umum, dan memiliki klasifikasi fungsi jalan yang lebih tinggi daripada ruas jalan lainnya sebagai jalan kabupaten, serta menghubungkan antar kabupaten. Jika pemerintah daerah melaksanakan alternatif I ini dengan asumsi bahwa pemerintah konsisten mengalokasikan anggaran penanganan jalan yang ada untuk ruas-ruas jalan pada pilihan ini, maka dengan rata-rata anggaran peningkatan jalan yaitu sebesar Rp 50 Miliar tahun ${ }^{-1}$ (APBD Kabupaten Tana Toraja 2010 - 2012) dan biaya peningkatan jalan sebesar rata-rata $\mathrm{Rp} 1$ Miliar $\mathrm{km}^{-1}$ (data anggaran proyek jalan Dinas PU Kab. Tana Toraja, 2012), akan tuntas dalam jangka waktu lebih kurang 4.5 tahun.

2. Alternatif II dengan total panjang jalan $255.4 \mathrm{~km}$, yang terdiri atas: (i). Batupapan - Rantekurra dengan panjang $16.9 \mathrm{~km}$; (ii). Kokkang - Buakayu dengan panjang $25.4 \mathrm{~km}$; (iii). Pasobo - Kondodewata dengan panjang $73.5 \mathrm{~km}$; (iv). Makale - Kaduaja dengan panjang $31.3 \mathrm{~km}$; (v). Tetebassi - Kondoran dengan panjang $8.6 \mathrm{~km}$; (vi). Jalan lingkar wisata dengan panjang $99.7 \mathrm{~km}$.

Untuk alternatif II ini meliputi seluruh ruas pada alternatif I ditambah ruas Makale - Kaduaja. Pertimbangan memilih penambahan ruas tersebut adalah karena adanya salah satu obyek wisata yang dapat dilalui yaitu agrowisata pango-pango untuk menghubungkan Kecamatan Makale sebagai pusat pelayanan (hirarki I) dengan Kecamatan Gandangbatu Sillanan sebagai subpusat pelayanan (hirarki II). Jika pemerintah daerah melaksanakan alternatif II ini dengan asumsi bahwa pemerintah konsisten mengalokasikan anggaran penanganan jalan yang ada untuk ruas-ruas jalan pada pilihan ini, maka dengan rata-rata anggaran peningkatan jalan yaitu sebesar $\mathrm{Rp}$ 50 Miliar tahun $^{-1}$ (APBD Kabupaten Tana Toraja 2010 - 2012) dan biaya peningkatan jalan sebesar rata-rata Rp 1 Miliar km ${ }^{-1}$ (data anggaran proyek jalan Dinas PU Kabupaten Tana Toraja, 2012), akan tuntas dalam jangka waktu lebih kurang 5.2 tahun.

Dengan terwujudnya salah satu alternatif prioritas jaringan jalan tersebut, maka akan mempermudah arus keluar masuk orang, barang, dan jasa sehingga akan meningkatkan pertumbuhan ekonomi wilayah. Pertumbuhan ekonomi wilayah yang meningkat akan mendorong peningkatan di sektor-sektor lainnya. Dengan demikian, hubungan fungsi antara pusat wilayah dan daerah hinterland tercipta dan terlaksana dengan baik sehingga akan saling mendukung dalam pertumbuhan wilayahnya.

\section{SIMPULAN}

Jaringan jalan di Kabupaten Tana Toraja pada umumnya telah sesuai dengan potensi-potensi wilayah yang ada, namun sebagian besar kondisinya rusak (74\%). Berdasarkan indeks perkembangan wilayah, Kecamatan Makale dan Makale Utara berada pada hirarki I yang menjadi pusat pelayanan; Kecamatan Gandasil, Mappak, Bonggakaradeng, Kurra, dan Sangalla berada pada hirarki II yang menjadi sub-pusat pelayanan; Kecamatan 
Simbuang, Rano, Rembon, Masanda, Bittuang, Saluputti, Malimbong Balepe, Makale Selatan, Mengkendek, Sangalla Selatan, Sangalla Utara, dan Rantetayo berada pada hirarki III yang merupakan daerah hinterland.

Dari hasil persepsi responden, prioritas perencanaan jaringan jalan di Kabupaten Tana Toraja lebih diutamakan berdasarkan potensi wilayah terutama obyek wisata, sementara berdasarkan aksesibilitas terutama kondisi jalan.

Untuk pengembangan wilayah Kabupaten Tana Toraja, maka jaringan jalan yang dapat diprioritaskan adalah :

i). Alternatif I dengan total panjang jalan $224.1 \mathrm{~km}$, yang terdiri atas: (i). Batupapan - Rantekurra dengan panjang $16.9 \mathrm{~km}$; (ii). Kokkang - Buakayu dengan panjang $25.4 \mathrm{~km}$; (iii). Pasobo - Kondodewata dengan panjang $73.5 \mathrm{~km}$; (iv). Tetebassi - Kondoran dengan panjang $8.6 \mathrm{~km}$; (v). Jalan lingkar wisata dengan panjang $99.7 \mathrm{~km}$.

ii). Alternatif II dengan total panjang jalan $255.4 \mathrm{~km}$, yang terdiri atas: (i). Batupapan - Rantekurra dengan panjang $16.9 \mathrm{~km}$; (ii). Kokkang - Buakayu dengan panjang $25.4 \mathrm{~km}$; (iii). Pasobo - Kondodewata dengan panjang $73.5 \mathrm{~km}$; (iv). Makale - Kaduaja dengan panjang $31.3 \mathrm{~km}$; (v). Tetebassi - Kondoran dengan panjang $8.6 \mathrm{~km}$; (vi). Jalan lingkar wisata dengan panjang $99.7 \mathrm{~km}$.

\section{UCAPAN TERIMA KASIH}

Penulis menyampaikan terima kasih yang setinggitingginya kepada Pusbindiklatren Bappenas yang telah memberikan beasiswa hingga penelitian ini dapat selesai.

\section{DAFTAR PUSTAKA}

[BPS] Badan Pusat Statistik. 2012. Tana Toraja Dalam Angka. Kabupaten Tana Toraja.

Christofakis, M. and A. Papadaskalopoulos. 2011. The growth poles strategy in regional planning: the recent experience of greece. Econ Paper, 6: 5-20.

Menteri Pekerjaan Umum. 2010. Peraturan Menteri $P U$ No.14/PRT/M/2010. Kementerian Pekerjaan Umum. Jakarta.

[Pemda] Kabupaten Tana Toraja. 2012. Anggaran Pendapatan dan Belanja Daerah. Pemerintah Daerah Kabupaten Tana Toraja. Makale.

Rustiadi, E., S.H. Sunsun, dan D.R. Panuju. 2011. Perencanaan dan Pengembangan Wilayah. Pustaka Obor Indonesia dan Crestpent Press. Jakarta.

Saaty, T.L. and M. Sodenkamp. 2008. Making decisions in hierarchic and network systems. International Journal of Applied Decision Sciences, I: 1-10.

Taiwo, A. and K. Francis. 2013. An appraisal of road condition effect on rural transportation in sekyere central district of the ashanti region of Ghana. $J$ Transportation Technolog, 3: 266271.doi:10.4236/jtts.2013.34028.

Tarigan, R. 2009. Perencanaan Pembangunan Wilayah. PT. Bumi Aksara. Jakarta. 